\title{
Direct closure of ventricular septal defect for left ventricular outflow tract obstruction in interrupted aortic arch
}

\author{
Jerome Soquet, MD, ${ }^{a}$ Melissa G. Y. Lee, MBBS, ${ }^{\mathrm{a}, \mathrm{b}, \mathrm{c}}$ and Christian P. Brizard, MS, MD, ${ }^{\mathrm{a}, \mathrm{b}, \mathrm{c}}$ Parkville, \\ Victoria, Australia
}

\author{
From the ${ }^{\mathrm{a}}$ Department of Cardiac Surgery, Royal Children's Hospital; ${ }^{\mathrm{b}}$ Department of Paediatrics, University of \\ Melbourne; and ${ }^{\mathrm{c}}$ Murdoch Childrens Research Institute, Parkville, Victoria, Australia. \\ Disclosures: Authors have nothing to disclose with regard to commercial support. \\ Received for publication June 20, 2017; accepted for publication July 21, 2017; available ahead of print Sept 13, \\ 2017. \\ Address for reprints: Christian P. Brizard, MS, MD, Department of Cardiac Surgery, Royal Children's Hospital \\ Melbourne, 50 Flemington Rd, Parkville, Victoria 3052, Australia (E-mail: christian.brizard@ @rch.org.au). \\ J Thorac Cardiovasc Surg 2017; 154:2041-3 \\ $0022-5223 / \$ 36.00$ \\ Copyright $(\underset{2017}{ } 20 y$ The American Association for Thoracic Surgery \\ http://dx.doi.org/10.1016/j.jtcvs.2017.07.076
}

Video clip is available online.

Interrupted aortic arch type B is associated with posterior deviation of the conal septum ${ }^{1}$ with potential left ventricular outflow tract (LVOT) obstruction (LVOTO) after repair, more specifically when there is an aberrant right subclavian artery. We describe a technique for direct closure of the ventricular septal defect (VSD) to realign the conal septum and prevent LVOTO. This procedure was used in 5 patients in our institution.

\section{SURGICAL TECHNIQUE}

In one stage, the aortic arch is repaired with an end-toside anastomosis ${ }^{2}$; then the aortic valve is gently probed through the tricuspid valve and the VSD with Hegar dilators. It is deemed adequate when equal to or greater than $4 \mathrm{~mm}$ for small babies and $5 \mathrm{~mm}$ for babies larger than $3 \mathrm{~kg}$. Last, the VSD is closed (Figure 1, A). Preoperative echocardiographic studies usually demonstrate the deviation of the infundibular septum very eloquently (Figure 2, $A$ ) but always undersize the aortic valve.

Interrupted 6-0 and 7-0 polypropylene mattress sutures on pericardial pledgets are used. The penetration points on the conal septum are precisely at its apex. On the inferior margin of the VSD, while away from the tricuspid valve annulus, they are on the left ventricular aspect of crest of the VSD. Close to the tricuspid annulus and the conduction tissue, small 7-0 bites are taken inferiorly. Tying the sutures aligns the LVOT (Figure 1, $B$, and Figure 2, $B$ ) and the left ventricular pressure further opens the LVOT on the beating heart. The technique derives from the description by

\section{RESULTS}

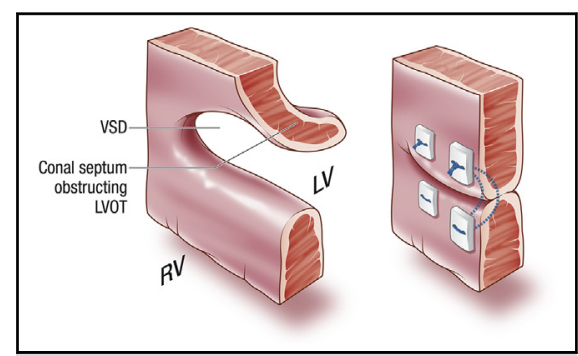

Relief of LVOTO by direct closure of the VSD in a patient with interrupted aortic arch.

\section{Central Message}

Direct ventricular septal defect closure in interrupted aortic arch type B is a simple and effective technique to align the conal septum and to prevent left ventricular outflow tract obstruction.

See Editorial Commentary page 2044.

Luciani and colleagues, ${ }^{3}$ who used a VSD patch closure to pull the conal septum anteriorly (Video 1 ).

This procedure was initiated in our institution after we saw an early recurrence of LVOTO in a patient whose VSD was initially closed with a treated pericardial patch. At reoperation, 20 days after the primary repair, the patch was removed. The defect was then closed with interrupted sutures, correcting the LVOTO.

Five patients have undergone this procedure in our institution since 2009. Median age was 5 days (range, 4-18 days), and median weight was $2.9 \mathrm{~kg}$ (range, 2.8$3.3 \mathrm{~kg}$ ). All patients had interrupted aortic arch type B, and 3 had an aberrant right subclavian artery. Three patients had a 22q11 microdeletion and 1 had a VACTERL association (vertebral defects, anal atresia, cardiac defects, tracheoesophageal fistula, renal anomalies, and limb abnormalities). Median aortic valve diameter at birth was $0.46 \mathrm{~cm}$ (range, $0.42-0.58 \mathrm{~cm}$ ), and 4 patients had a bicuspid aortic valve. Median hospital stay was 16 days (range, 11-29 days). All patients are currently alive after a median follow-up of 6.1 months (range, 2.839.5 months). The first patient was reoperated on for a LVOTO resection 1.6 years after the procedure, with a 

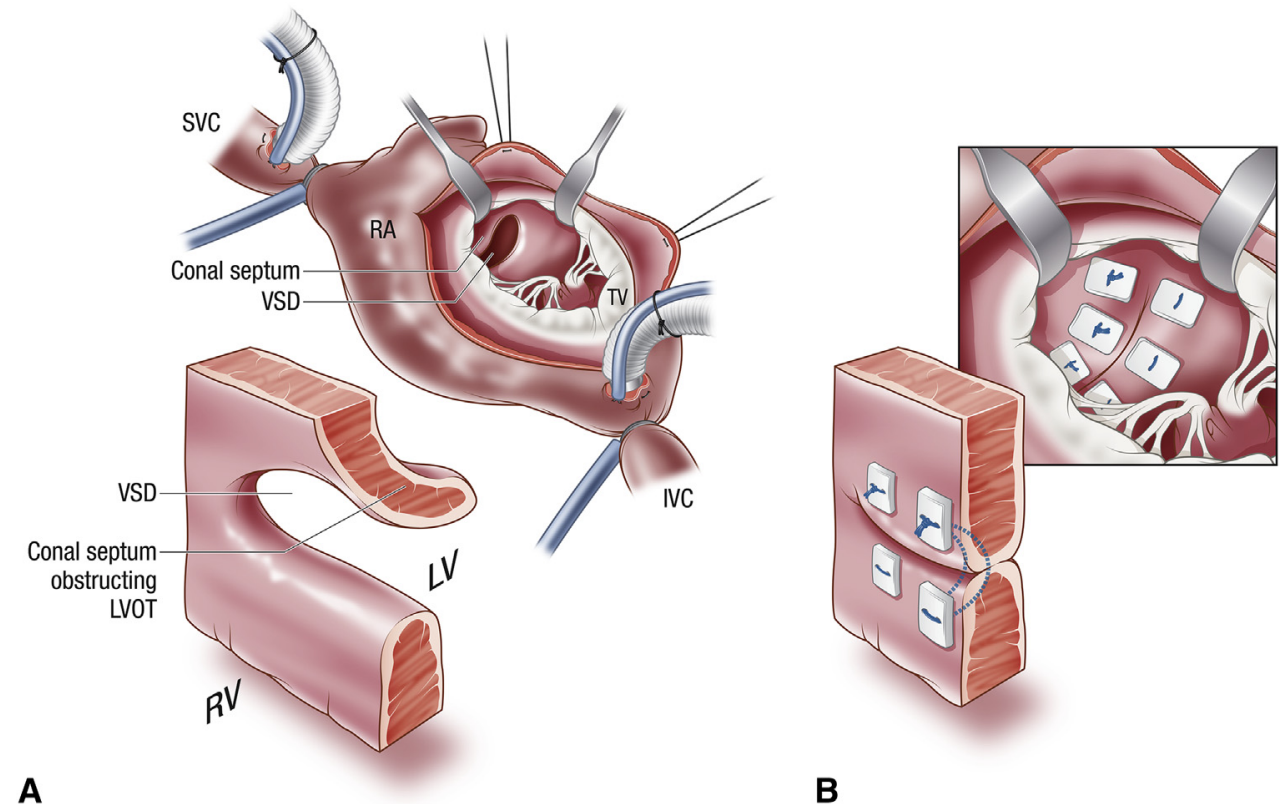

B

FIGURE 1. A, Illustration of the perimembranous ventricular septal defect (VSD) with a left ventricular outflow tract (LVOT) obstruction caused by the posterior deviation of the conal septum preoperatively. B, The left ventricular outflow tract obstruction is relieved by pulling the conal septum anteriorly after direct closure of the ventricular septal defect with interrupted sutures on pledgets. $S V C$, Superior vena cava; $R A$, right atrium; $T V$, tricuspid valve; $I V C$, inferior vena cava; $L V$, left ventricle; $R V$, right ventricle.

residual peak gradient of $19 \mathrm{~mm} \mathrm{Hg}$ after 4.3 years of follow-up. The remaining patients had an unobstructed LVOT at last follow-up. In addition, 3 patients had a trivial residual VSD during the early postoperative period; none, however, had a residual VSD on the most recent echocardiographic study.

\section{DISCUSSION}

Many strategies have been described to prevent a LVOTO in this anatomic setting. ${ }^{4}$ The Damus-Kaye-Stansel anastomosis is included in the Yasui procedure to bypass the LVOT. ${ }^{5}$ A univentricular approach with a Damus-Kaye-Stansel has also been described, either as a temporary measure to allow for growth of the LVOT or as a permanent bailout procedure. Other, less aggressive strategies include the risky attempt at resecting the conal septum. These radical approaches have been devised on the assumption that the LVOT was a fixed setup and a combination of small aortic annulus and deviation of the conal septum.
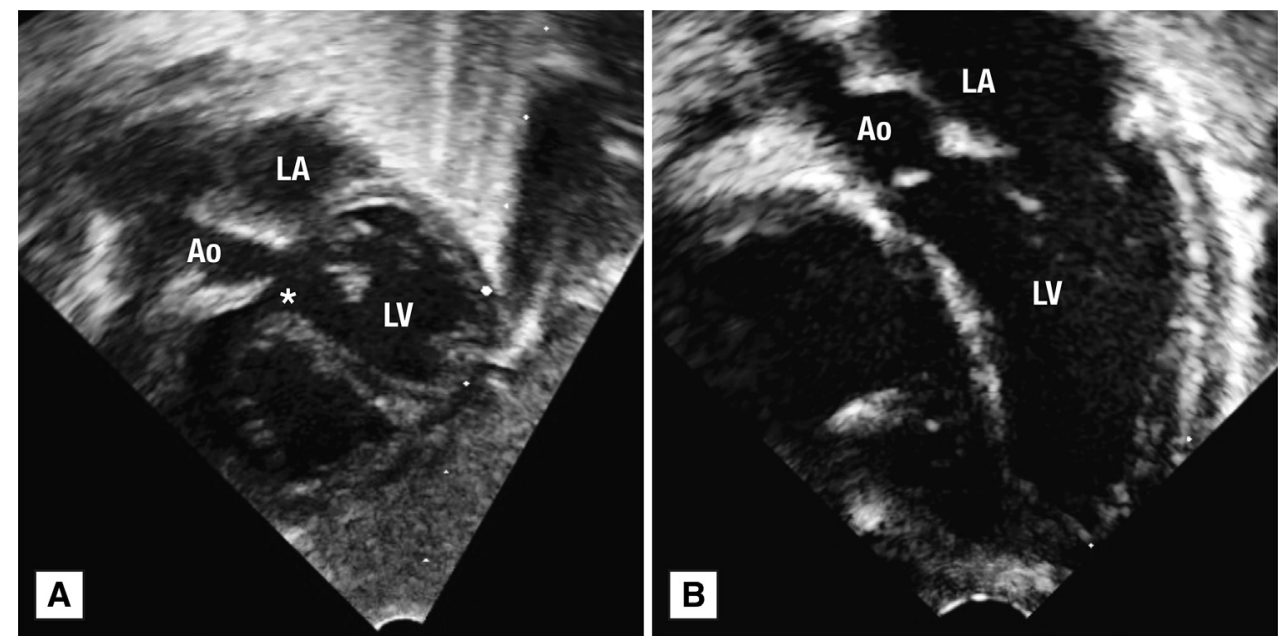

FIGURE 2. Transthoracic echocardiographic study focused on the ventricular septal defect (asterisk) and the left ventricular outflow tract preoperatively (A) and postoperatively (B). $L A$, Left atrium; $A o$, aorta; $L V$, left ventricle. 


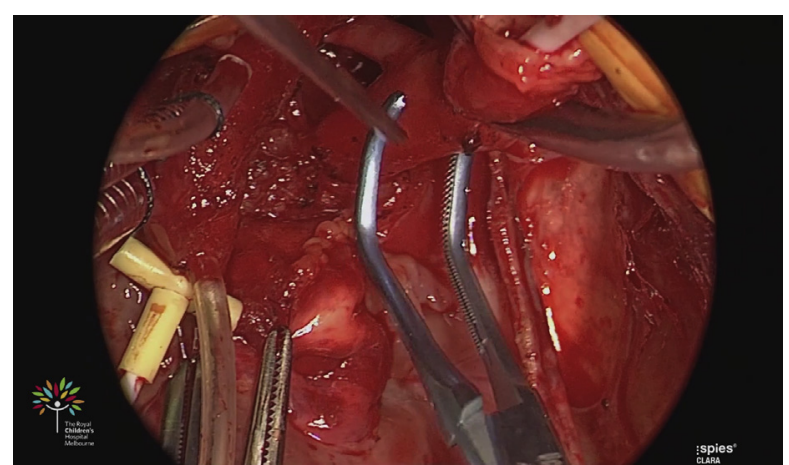

VIDEO 1. Surgical video describing our technique to repair the aortic arch and correct left ventricular outflow tract obstruction with a direct ventricular septal defect closure in a patient with interrupted aortic arch type B. Video available at: http://www.jtcvsonline.org/article/S0022-5223(17) 31767-1/fulltext.

The LVOTO is never demonstrated hemodynamically preoperatively, because the VSD creates an unrestrictive outlet to the left ventricle, but the anatomic setup for a postoperative obstruction is suspected on the preoperative investigations. The efficacy of the approach described here demonstrates that the conal septum is mobile and can be realigned and that the aortic valve is adequate. Approaches involving VSD patches do not generate enough stress on the infundibular septum to realign the LVOT. Moreover, the left ventricular pressure in systole increases the malalignment of the VSD patch with the deviated conal septum.

The technique is simple and reproducible, and it completely relieves the LVOTO. In our unit, we have in the past also relied on other technical tricks to try to align the infundibular septum. These have included attempts at resection or the use of a smaller and slitlike VSD patch. The Yasui procedure, ${ }^{5}$ when the aortic valve was adequate, was also used in 2 patients during the same time span (surgeon's preference), with 1 death. On the other hand, we have never used a univentricular strategy, even as an intermediate stage.

\section{References}

1. Moulaert AJ, Bruins CC, Oppenheimer-Dekker A. Anomalies of the aortic arch and ventricular septal defects. Circulation. 1976;53:1011-5.

2. Hussein A, Iyengar AJ, Jones B, Donath SM, Konstantinov IE, Grigg LE et al. Twenty-three years of single-stage end-to-side anastomosis repair of interrupted aortic arches. J Thorac Cardiovasc Surg. 2010;139:942-7. 949; discussion 948

3. Luciani GB, Ackerman RJ, Chang AC, Wells WJ, Starnes VA. One-stage repair of interrupted aortic arch, ventricular septal defect, and subaortic obstruction in the neonate: a novel approach. J Thorac Cardiovasc Surg. 1996;111:348-58.

4. Alsoufi B, Schlosser B, McCracken C, Sachdeva R, Kogon B, Border W, et al Selective management strategy of interrupted aortic arch mitigates left ventricular outflow tract obstruction risk. J Thorac Cardiovasc Surg. 2016;151: 412-20.

5. Yasui H, Kado H, Nakano E, Yonenaga K, Mitani A, Tomita Y, et al. Primary repair of interrupted aortic arch and severe aortic stenosis in neonates. J Thorac Cardiovasc Surg. 1987;93:539-45. 